\title{
REINVESTIGAÇÃO DA CONÍFERA PERMIANA KRAUSELCLADUS (FORMAÇÃO TERESINA, BACIA DO PARANÁ, BRASIL): NOVAS INTERPRETAÇÕES MORFOLÓGICAS E ANATÔMICAS
}

\author{
JEAN CARLO MARI FANTON, FRESIA RICARDI-BRANCO \\ DGRN, IG, UNICAMP, Cx. P. 6152, 13083-970, Campinas, SP, Brasil.jeanfanton@ige.unicamp.br \\ fresia@ige.unicamp.br \\ MARGARITA TORRES DE RICARDI \\ Centro Jardín Botânico, FC/ ULA, Mérida,Venezuela.cjbot@ciens.ula.ve \\ ROSEMARIE ROHN \\ DGA/IGCE, UNESP, Cx. P.178, 13506-900, Rio Claro, SP, Brasil.rohn@rc.unesp.br
}

\begin{abstract}
RESUMO - A partir do final do Eopermiano, regiões do Gondwana Ocidental, incluindo a bacia do Paraná, tornaram-se gradualmente áridas. Essa crescente aridização que foi registrada, em parte, nas rochas sedimentares da Formação Teresina, vincula-se a um contexto climático e tectônico global e induziu severas modificações florísticas. O gênero Krauselcladus é uma conífera representada por ramos de várias ordens, procedentes de um único afloramento da porção superior da Formação Teresina, em Canoinhas, Santa Catarina, sul do Brasil, de idade provavelmente eoguadalupiana. Alguns exemplares do Carbonífero da Argentina também foram atribuídos ao mesmo gênero. Novas análises dos exemplares brasileiros evidenciaram que os ramos são densamente cobertos por folhas decorrentes, de morfótipos linear e lobado, com a cutícula geralmente preservada. Estudos morfológicos e anatômicos permitiram emendar a diagnose genérica, discutir a validade das espécies descritas e sinonimizar Krauselcladus catarinensis com K. canoinhensis. Posicionou-se o gênero dentro da Ordem Coniferales, com base na presença de ductos resiníferos esquizógenos refletidos na epiderme foliar. Características epidérmicas tais como paredes espessas com abundantes pontuações nas células epidérmicas, estômatos afundados e ductos resiníferos corroboram as condições climáticas interpretadas para a Formação Teresina.
\end{abstract}

Palavras-chave: Krauselcladus, Coniferales, Guadalupiano, Formação Teresina, bacia do Paraná.

ABSTRACT - REINVESTIGATION OF THE PERMIAN CONIFER KRAUSELCLADUS (TERESINA FORMATION, PARANÁ BASIN, BRAZIL): NEW MORPHOLOGICAL AND ANATOMICAL INTERPRETATIONS. At the end of the Early Permian, many regions in Western Gondwana, including the Paraná Basin, became gradually arid. This increasing aridity, partly evidenced in the Teresina Formation, was related to a global climatic and tectonic context and caused severe floristic modifications. The genus Krauselcladus is a conifer represented by distinct branch orders found in a single outcrop of the upper Teresina Formation in Canoinhas, Santa Catarina, South Brazil, probably early Guadalupian in age. Some fossil plants from the Upper Carboniferous of Argentina were also assigned to this genus. The branches of Krauselcladus from Brazil are densely covered by decurrent, linear and lobed leaves, which cuticle was usually preserved. Morphological and anatomical studies allow to improve the diagnosis of the genus, discuss the validity of the species and synonymies Krauselcladus catarinensis with as a junior synonym of $K$. canoinhensis. The genus is included in the Order Coniferales, according to the presence of schizogenous resin ducts in the leaf epidermis. The epidermal characters, such as thick walls with abundant epidermal cell pits, sunken stomata and resin ducts, corroborate the climatic conditions ascribed to the Teresina Formation.

Key words: Krauselcladus, Coniferales, Guadalupian, Teresina Formation, Paraná Basin. 


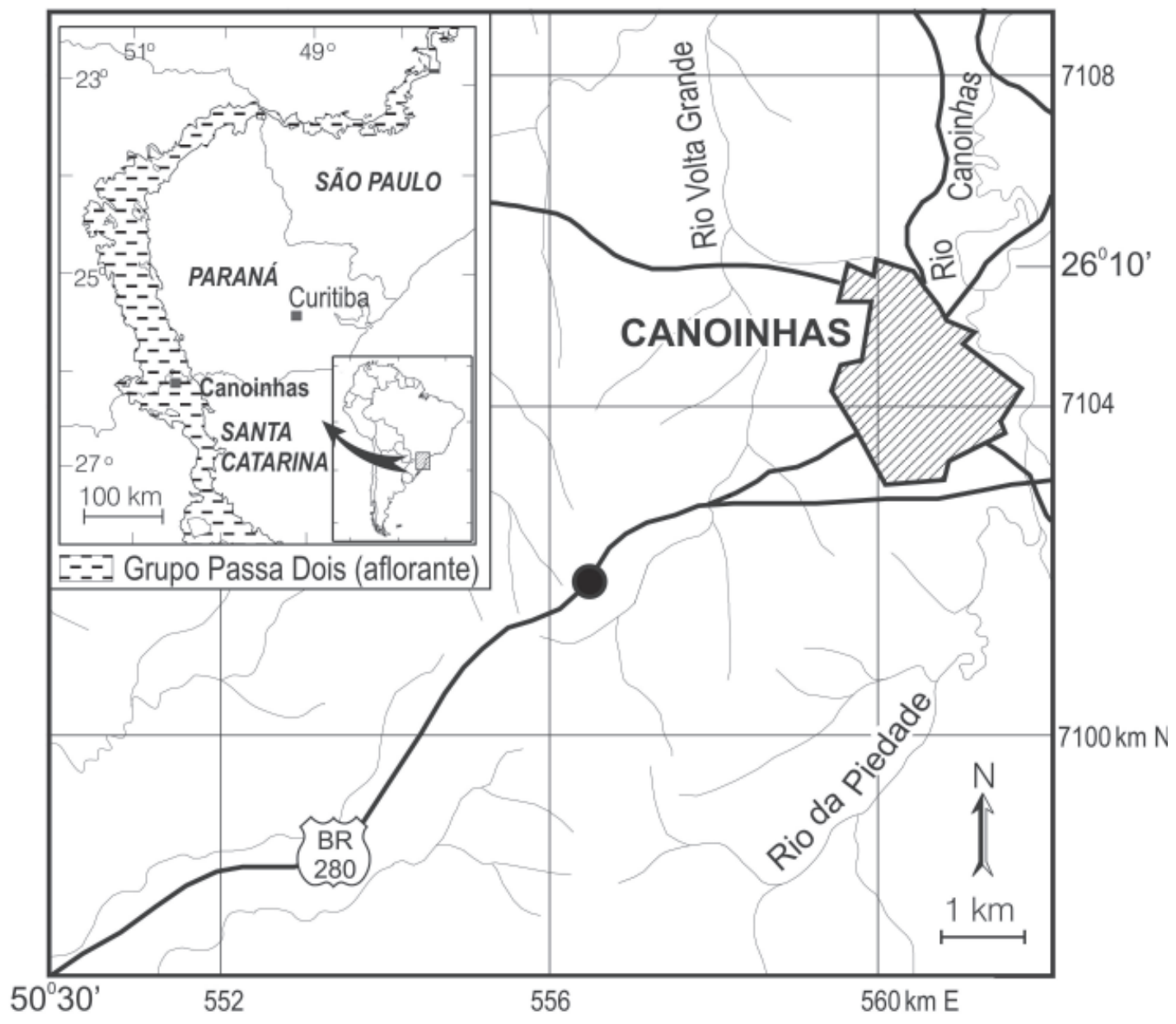

Figura 1. Mapa de localização do afloramento estudado (círculo).

Figure 1. Location map of the studied outcrop (circle).

\section{INTRODUÇÃO}

O gênero Krauselcladus é a única conífera formalmente conhecida da porção gonduânica brasileira atribuível ao Guadalupiano. Exclusivo da Formação Teresina (Santa Catarina), Grupo Passa Dois, bacia do Paraná, Krauselcladus foi descrito por Yoshida (1970) que definiu duas espécies: $K$. canoinhensis Yoshida e K. catarinensis Yoshida. A única espécie do gênero conhecida fora do Brasil é K. argentinus (Archangelsky, 1978). O principal objetivo deste estudo foi aprimorar o conhecimento morfológico e discutir a validade das espécies propostas por Yoshida (1970), bem como compará-las com K. argentinus, através da análise de novos exemplares e da reavaliação de características anatômicas. Desta forma, buscou-se uma melhor caracterização e posicionamento do gênero dentro do grupo das coníferas.

As rochas sedimentares do Grupo Passa Dois (Figura 1), especialmente as da Formação Teresina, evidenciam ciclos climáticos úmidos a secos de longa duração, com tendência de aumento gradual das condições de aridez. Essa aridização que afetou a bacia do Paraná é também registrada em outras áreas do planeta, podendo ser interpretada como um evento global (Crowley \& North, 1991; Rohn, 1994; Anderson et al.,
1999). Tal tendência climática iniciada no Permiano e que continuou durante a Era Mesozóica, como conseqüência da formação do Pangea, permitiu a irradiação das coníferas, melhor adaptadas ao déficit hídrico (Wing \& Sues, 1992).

As coníferas permianas das províncias paleoflorísticas euro-americana e angárica têm recebido especial atenção por parte dos paleobotânicos devido a sua excelente preservação e abundância (Clement-Westerhof, 1988; Meyen, 1997). Contudo, as coníferas que se desenvolveram no Gondwana têm sido menos estudadas. Até o momento, algumas coníferas gonduânicas guadalupianas-lopingianas foram descritas na África do Sul (Anderson \& Anderson, 1985), Índia (Pant, 1982, 1996) e Austrália (White, 1998). Krauselcladus representa o único gênero conhecido de conífera atribuível ao Guadalupiano da porção gondwânica brasileira e é fundamental na interpretação da história evolutiva do grupo no Gondwana ocidental.

\section{ÁREA DE ESTUDO}

As amostras estudadas foram coletadas no Estado de Santa Catarina (SC), região sul do Brasil, encontradas apenas em um afloramento da parte superior da Formação Teresina, 
localizado no município de Canoinhas (Figura 1), na BR 280 (entre Canoinhas e Porto União), cerca de $6 \mathrm{~km}$ a sudoeste do trevo principal da cidade $\left(26^{\circ} 11^{\prime} 59.8^{\prime \prime} \mathrm{S}, 50^{\circ} 25^{\prime} 58.8^{\prime \prime} \mathrm{W}\right)$.

O depósito com Krauselcladus localiza-se praticamente no acostamento da estrada, em sua margem sul, correspondendo a arenitos muito finos calcíferos cinza claros com cerca de $40 \mathrm{~cm}$ de espessura (Figura 2). Sob estes depósitos foi possível observar alguns estratos de siltitos e arenitos finos com gretas de contração, parcialmente encobertos, somando mais do que $5 \mathrm{~m}$ de espessura. Um pouco acima do arenito com os ramos de coníferas, a exposição torna-se melhor numa pedreira abandonada na margem norte da estrada, onde predominam argilitos e arenitos muito finos interlaminados, formando acamamento wavy (Figura 2). Ocorrem alguns arenitos com estratificações cruzadas por ondas, provavelmente induzidas por tempestades. Há uma intercalação decimétrica de oosparito na parte inferior da pedreira, uma porção com abundantes diques clásticos na parte média e uma coquina de bivalves na parte superior. Essa coquina, além de apresentar bivalves como Pinzonella neotropica, espécie típica da parte superior da Formação Teresina, inclui também raros caules de licófitas (provavelmente pertencentes a Lycopodiopsis derbyi) e abundantes folhas de licófitas, ambos permineralizados por sílica.

Embora o arenito calcífero com Krauselcladus seja bastante compacto e não permita expor facilmente os níveis fossilíferos, é possível notar que os ramos das coníferas se concentram em diversos planos superpostos, espaçados verticalmente entre si cerca de 0,5 a 2,0 cm. Os ramos também são abundantes ao longo de um plano, onde se dispõem de modo moderadamente denso (um a três fragmentos de ramos por área de $100 \mathrm{~cm}^{2}$ ), mas normalmente não ocorre sobreposição de diversos ramos num único plano.

A Formação Teresina representa um extenso ambiente deposicional caracterizado por águas muito rasas, com substrato quase horizontal, sem conexão bem evidenciada com o oceano (Rohn, 1994; Rohn et al., 2004). No âmbito da gradual aridização da região da bacia do Paraná devem ter ocorrido oscilações climáticas cíclicas, alternando-se condições ora mais secas, ora mais úmidas, as quais provavelmente controlaram as variações do nível da água e a sua salinidade (Rohn, 1994; Rohn et al., 2004). Os intervalos mais secos devem ter promovido a exposição de grandes áreas e aumento da salinidade da água. Estas áreas, sujeitas à inundação durante tempestades, provavelmente eram ocupadas por comunidades vegetais dominadas por licófitas herbáceas que suportavam substratos encharcados por águas salobras a salinas. A tolerância e adaptação das licófitas paleozóicas a tais condições vêm sendo discutidas em diversos trabalhos (e.g., Gastaldo, 1986; Dimichele \& Demaris, 1987).

Ao contrário das licófitas, relativamente abundantes na Formação Teresina, esfenófitas, filicíneas, glossopterídeas e outros vegetais são muito mais raros, devendo refletir o seu caráter mais continental e as distâncias maiores entre os seus ambientes de vida e os ambientes deposicionais, mas talvez também o clima relativamente seco.

Na Formação Rio do Rasto, unidade que se sobrepõe à Formação Teresina, depositada em condições totalmente continentais e periodicamente muito secas, as licófitas desaparecem e esfenófitas, filicíneas e glossopterídeas ocorrem em maior abundância (Rohn, 1994). O desaparecimento das licófitas deve estar relacionado à redução de salinidade nos ambientes aquáticos, cujas margens passaram a ser ocupadas predominantemente por esfenófitas. Até o momento, não há evidências sobre a presença de coníferas na Formação Rio do Rasto. Por outro lado, também são muito mal representadas estruturas reprodutivas de vegetais, embora folhas e/ou caules sejam abundantes, permitindo interpretar que ocorreu forte controle tafonômico na composição das assembléias fossilíferas.

\section{MATERIAL E MÉTODOS}

Os exemplares estudados encontram-se preservados como compressões. As abundantes cutículas preservadas permitiram a realização do estudo da anatomia das folhas de Krauselcladus.

A análise dos exemplares baseou-se na observação dos holótipos e parátipos depositados nas coleções científicas do Instituto de Geociências da Universidade de São Paulo (IGc-USP) e do Instituto de Geociências e Ciências Exatas da Universidade Estadual de São Paulo Júlio de Mesquita Filho - Campus de Rio Claro (UNESP- Rio Claro). Todas as amostras contendo fragmentos de ramos bem preservados foram fotografadas em câmara digital NIKON (Coolpix 3100) para posterior comparação. A análise morfológica prosseguiu a partir da observação minuciosa sob estereomicroscópio óptico (LEICA/Zoom 2000) e esquematização das estruturas em vários aumentos. Os fragmentos de ramos tiveram suas estruturas individualizadas, caracterizadas (as folhas quanto à filotaxia, forma, margem, base e ápice, padrão de nervura, etc.), mensuradas (comprimento e largura, em mm, dos eixos e das folhas), além de desenhadas. Desse conjunto, quatro amostras foram selecionadas para os estudos cuticulares, contendo numerosos fragmentos de ramos de todas as ordens, bem preservados (IGc-USP: GP/3E 0241, 4913 e 6014. UNESP- Rio Claro: URC/CO 41). As cutículas foram obtidas por maceração em bloco (Kerp, 1990, 1996) mergulhando-os durante o período de quinze minutos em $\mathrm{HCl}(50 \%)$, seguido por ataque com HF por aproximadamente quarenta e cinco minutos, tempo no qual já se desprendiam numerosas cutículas. Em seguida, as cutículas foram três vezes lavadas com $\mathrm{H}_{2} \mathrm{O}$ destilada e posteriormente com $\mathrm{KOH}(10 \%)$. Com estas, foram confeccionadas cinqüenta lâminas (meio de inclusão Entellan) que foram observadas em Microscópio óptico (ZEISS/ Axioskop 40) e fotografadas (câmara ZEISS MC80DX acoplada). A partir deste conjunto de dados, realizou-se a descrição dos fósseis e sua comparação com outros taxa de acordo com a literatura pertinente. 


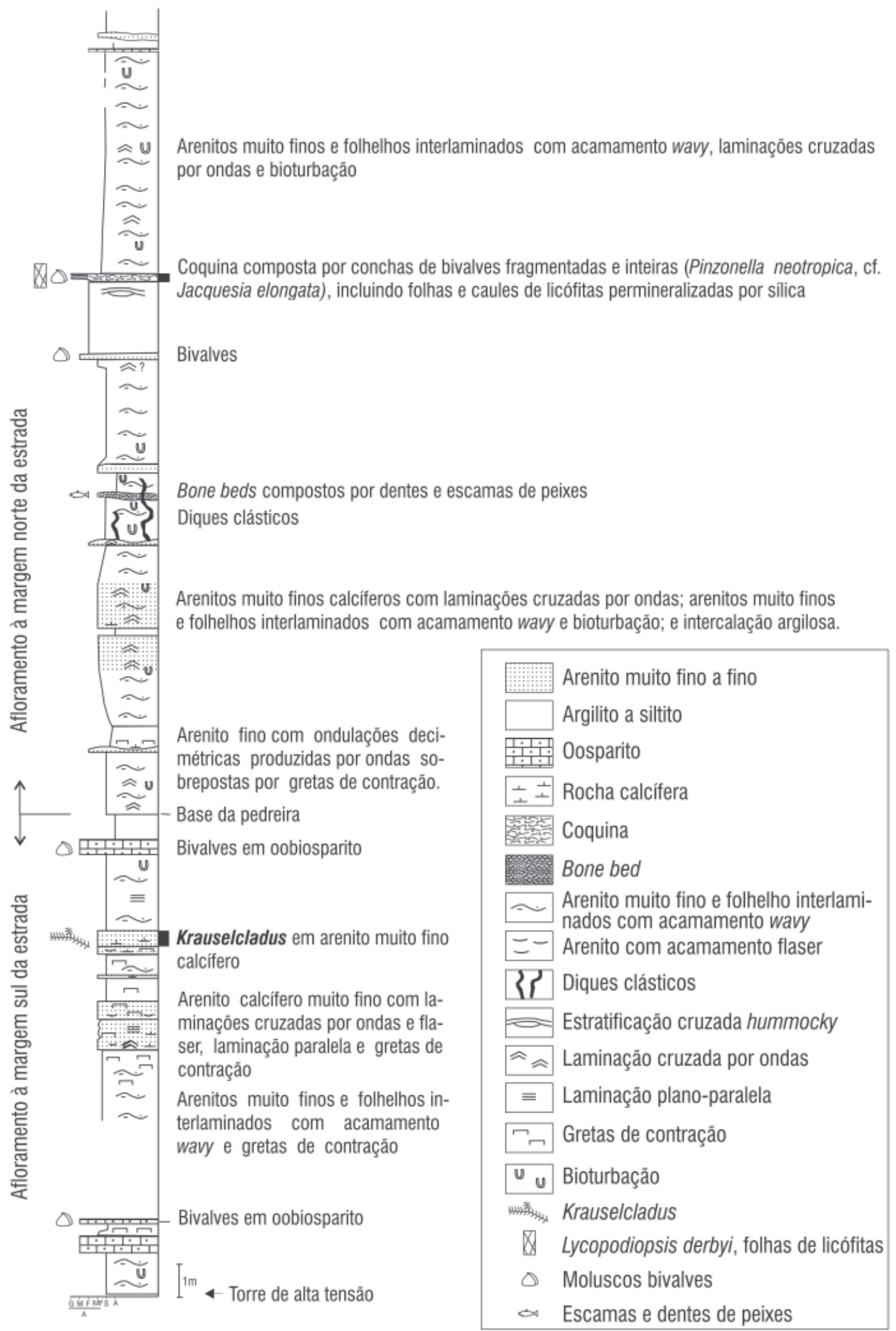

Figura 2. Seção colunar do afloramento localizado na BR 280, 6 km a oeste da cidade de Canoinhas (SC). Porção superior da Formação Teresina.

Figure 2. Columnar section of the outcrop located at the BR 280 road, $6 \mathrm{~km}$ West of Canoinhas (Santa Catarina State). Upper part of the Teresina Formation. 


\section{SISTEMÁTICA}

A classificação adotada para a divisão das traqueófitas foi o sugerido por Stewart \& Rotwell (2001). Para a descrição de Krauselcladus levou-se em consideração a diagnose original feita por Yoshida (1970), baseada na morfologia externa de ramos e folhas. Na presente caracterização foram incluídos caracteres epidérmicos, que no caso das coníferas são de crucial importância, facilitando o reconhecimento e caracterização dos táxons (Clement-Westerhof, 1984, 1987; Kerp, 1996).

\section{Classe GYMNOSPERMOPSIDA Ordem CONIFERALES \\ Gênero Krauselcladus Yoshida, 1970 emend.}

Espécie-tipo. Krauselcladus canoinhensis Yoshida, 1970. Diagnose genérica emendada. Ramos estéreis compostos, quatro ordens de ramificação, densamente cobertos por folhas, simples, sésseis, bifaciais, bases decorrentes, dispostas espiraladamente. Dois morfótipos básicos de folhas: linear e lobado, ambos com nervura central conspícua. Folhas lineares retas ou falcadas, apresentando ápice agudo, arredondado ou bífido, inseridas em ângulo agudo ou reto. Folhas lobadas bi ou multilobadas, de lobos arredondados, inseridas em ângulo reto e nervura central conspícua dividindo-se conforme o número de lobos. Folhas anfiestomáticas, células epidérmicas de paredes anticlinais grossas e levemente sinuosas, abundantes pontuações, sendo polimórficas, na porção proximal, ou retangulares, na porção médio-distal. Estômatos haploqueílicos, afundados e dispostos em fileiras longitudinais, na face abaxial, ou em grupos laxos, na face adaxial. Ductos resiníferos esquizógenos de paredes grossas. Margens lisas sem papilas ou tricomas.

Emended generic diagnosis. Compound sterile branches with four orders of branching, densely covered with simple, decurrent, spirally-inserted, sessile, bifacial leaves. Linear and lobed leaves, with conspicuous central vein. Linear leaves straight or falcate, with apex sharp, rounded or bifidate, inserted at acute or right angle. Lobed leaves with two or more rounded lobes, inserted at right angles, and conspicuous central vein divided according to the number of lobes. Amphistomatic leaves epidermal cells with thick, slightly wavy walls with abundant pits, being polymorphic in the proximal portion, and rectangular in the medial-distal portion. Haplochelic stomata, sunken and arranged in longitudinal rows on the abaxial face, or in lax groups on the adaxial face. Thick walled schizogenous resin ducts. Margins smooth without hairs or papillae.

Krauselcladus canoinhensis Yoshida, 1970 emend. (Figuras 3-6)

Krauselcladus catarinensis Yoshida. Yoshida, 1968:17-19, est.3, figs. 10-13 e est.4, figs. 16-18.
Krauselcladus catarinensis Yoshida. Yoshida, 1970:10-11, est.3, figs. $1-3$ e est. 4 , fig. 2.

Holótipo. IGc-USP GP/3T 1040.

Parátipos. IGc-USP: GP/3E 0240, 0241, 0536, 3764 a/b, 4912, 4913, 4914, 4915, 5240 e 6014. GP/3T 1036, 1037, 1038, 1039, 1041, 1042, 1043, 1046, 1056, 1057, 1058, 1059, 1060, 1061, 1065, 1066, 1067, 1068 e 1069. UNESP/Rio Claro: URC/CO 41 a, b, c, $\mathrm{d}, \mathrm{e}, \mathrm{f}, \mathrm{g}, \mathrm{h}$.

Lâminas. GP/3E 4913 (lâm. 03, 05, 06, 09, 16 e 17), GP/3E 6014 (Lâm. 10, 11, 13, 14, 21 e 38) e URC/CO 41 (Lâm. 31, 36 e 42).

Procedência. Rodovia BR 280 entre Canoinhas e Porto União, cerca de $6 \mathrm{~km}$ do trevo principal de Canoinhas (26 11'59. $8^{\prime \prime} \mathrm{S}$ e $50^{\circ} 25^{\prime} 58.8^{\prime \prime}$ W), Município de Canoinhas, Estado de Santa Catarina (SC), sul do Brasil.

Diagnose emendada. Aspectos morfológicos. Ramos vegetativos compostos portando ramificações de $1^{\mathrm{a}}, 2^{\mathrm{a}}, 3^{\mathrm{a}} \mathrm{e}$ $4^{\mathrm{a}}$ ordens. Ramos de $1^{\mathrm{a}}$ ordem medindo 6,5 a $19 \mathrm{~mm}$ de largura; de $2^{\mathrm{a}}$ ordem variam de 3,9 a 6,5 mm de largura; ramos de $3^{\mathrm{a}}$ ordem variam de 1,9 a $3,3 \mathrm{~mm}$ de largura e os ramos de $4^{\mathrm{a}}$ ordem variam de 0,8 a $1,7 \mathrm{~mm}$ de largura. Ramos de todas as ordens apresentam-se densamente cobertos por folhas heteromórficas sésseis, bifaciais, decorrentes, com nervura central conspícua de margens lisas e dispostas espiraladamente. As folhas lineares retas, inseridas em ângulo agudo, apresentam predominantemente ápice agudo ou arredondado, ou ainda bífido, em menor freqüência. As folhas lineares falcadas, inseridas predominantemente em ângulo agudo ou menos freqüente reto, apresentam ápice predominantemente agudo ou arredondado, ou ainda bífido ou recortado. Particularmente no ramo de $1^{\mathrm{a}}$ ordem, as folhas lineares falcadas atingem comprimentos e larguras superiores às das outras ordens. Folhas lobadas, predominantemente inseridas em ângulo reto, podendo ser bi ou multilobadas, com lobos arredondados e nervura central conspícua dividindo-se conforme o número dos lobos.

Aspectos anatômicos. Vista paradermal. Ambas as faces apresentam células epidérmicas polimórficas, com cinco ou seis lados, na porção proximal que, gradativamente são substituídas por células retangulares na porção médio-distal da folha, inclusive na nervura central conspícua. As células epidérmicas apresentam paredes anticlinais grossas levemente sinuosas e com abundantes pontuações. Estômatos haploqueílicos, afundados, rodeados por 5 a 8 células subsidiárias, dispostos em fileiras longitudinais quando abundantes ou dispostos em grupos laxos. Ductos resiníferos esquizógenos, de paredes grossas, com 5 a 8 células, dispostos em fileiras longitudinais nas porções marginal e mediana da folha. Margens lisas sem papilas e tricomas. Face abaxial caracterizada por abundantes estômatos dispostos em fileiras longitudinais. Face adaxial caracterizada por escassos estômatos.

Emended diagnosis. Morphological aspects. Compound vegetative branches with branching of the first, second, third and fourth orders. Branches of the first order measuring 6.5 to $19 \mathrm{~mm}$ in width; those of the second order varied from 3.9 to $6.5 \mathrm{~mm}$ in width; branches of the third order varied from 

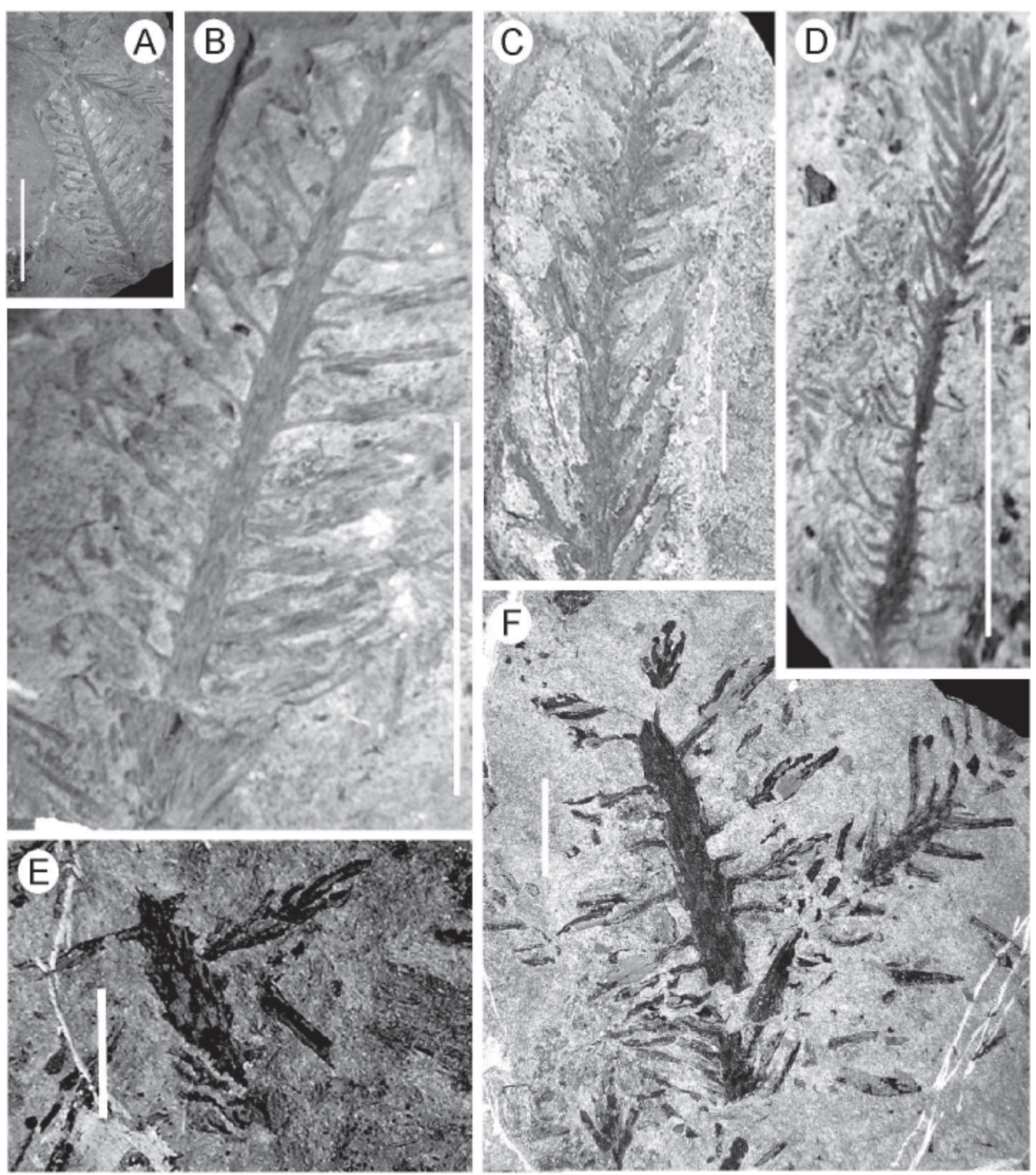

Figura 3. Krauselcladus canoinhensis emend. A-B, GP/3T 1040 holótipo, ramo de $2^{\text {a }}$ ordem com folhas heteromórficas (lineares e lobadas), escala $=50 \mathrm{~mm} ; \mathrm{C}, \mathrm{GP} / 3 \mathrm{E} 536$, ramo de $4^{\mathrm{a}}$ ordem com folhas heteromórficas, escala $=10 \mathrm{~mm} ; \mathrm{D}, \mathrm{GP} / 3 \mathrm{E} 6014$, ramo de $4^{\mathrm{a}}$ ordem com folhas lineares (retas e falcadas), escala $=50 \mathrm{~mm} ; \mathrm{E}-\mathrm{F}, \mathrm{GP} / 3 \mathrm{E} 241$, ramos $2^{\mathrm{a}}$ e $3^{\mathrm{a}}$ ordens com folhas multilobadas e lineares retas, escala $=10 \mathrm{~mm}$.

Figure 3. Krauselcladus canoinhensis emend. A-B, GP/3T 1040, holotype, second order branch covered with heteromorphic linear or lobed leaves, scale bar $=50 \mathrm{~mm}$; C, GP/3E 536, fourth order branch covered with heteromorphous leaves, scale bar = $10 \mathrm{~mm} ; \mathbf{D}, \mathrm{GP} / 3 \mathrm{E}$ 6014 , fourth order branch covered with linear straight and linear falcate leaves, scale bar $=50 \mathrm{~mm}$; E-F, GP/3E 241 , second and third order branches with multilobed and straight leaves, scale bar $=10 \mathrm{~mm}$.

1.9 to $3.3 \mathrm{~mm}$ in width, and those of the fourth order varied from 0.8 to $1.7 \mathrm{~mm}$ in width branches of all orders densely covered with heteromorphic, decurrent, sessile, bifacial leaves, with conspicuous central vein and smooth margins; leaves arranged in spiral. Linear leaves straight, inserted at acute angle, presents mainly sharp or rounded apices, but some are bifid. Linear leaves falcate, inserted at acute or right angle, presents mainly sharp or rounded apices, but some are bifid or cut. Especially on branches of the first order, the falcate linear leaves reach lengths and widths superior to those of the other orders. Lobed leaves predominantly inserted at right angles, with two or more rounded lobes and conspicuous central vein divided according to the number of lobes.

Anatomical aspects. Paradermal view. Both surfaces present polymorphic proximal epidermal cells with five or six sides, gradually being replaced by rectangular cells in the central and distal parts of the leaf, including the conspicuous central vein. The epidermal anticlinal walls thick and slightly wavy with abundant pits. Haplochelic stomata, sunken, surrounded by 5 to 8 subsidiary cells arranged in longitudinal rows when abundant, or arranged in lax groups. Schizogenous resin ducts with thick walls of 5 to 8 cells, arranged in longitudinal rows located along the 

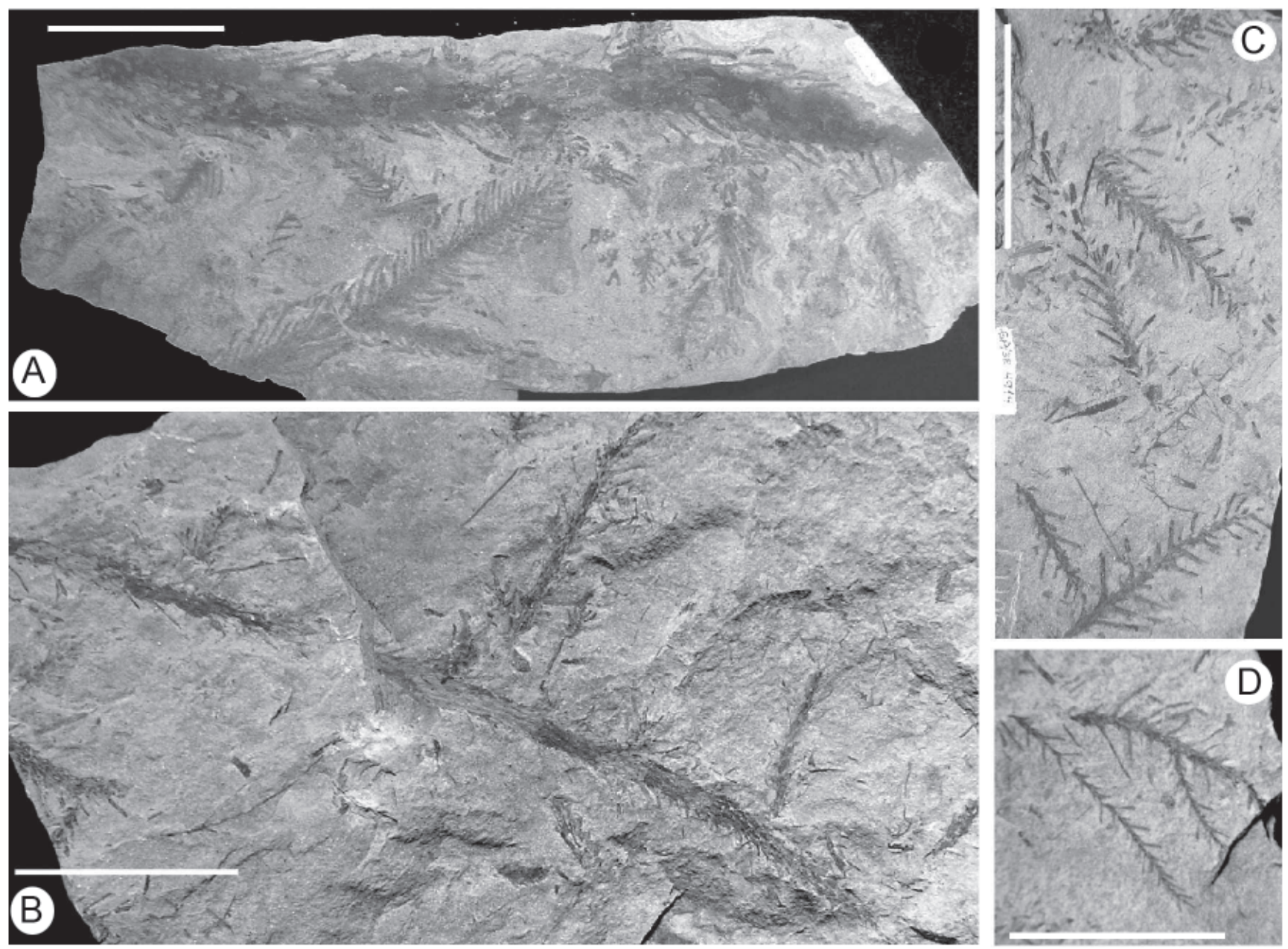

Figura 4. Krauselcladus canoinhensis emend. A, GP/3E 4912, ramos de $1^{\mathrm{a}}$, $2^{\mathrm{a}}$ e $3^{\mathrm{a}}$ ordens com folhas heteromórficas; B, GP/3E 3764b, ramos de $2^{a}, 3^{a}$ e $4^{a}$ ordens, notar comprimento e disposição dos ramos; C, GP/3E 4914, ramos de $3^{\mathrm{a}}$ ordem, notar comprimento e disposição dos ramos; D, GP/3E 5240, ramos de $3^{\mathrm{a}}$ e $4^{\mathrm{a}}$ ordem. Escalas $=50 \mathrm{~mm}$.

Figure 4. Krauselcladus canoinhensis emend. A, GP/3E 4912, branches of first, second and third orders covered with heteromorphous leaves; B, GP/3E 3764b, branches of second, third and fourth orders showing their length and disposition; C, GP/3E 4914, branches of third order showing their length and disposition; D, GP/3E 5240, branches of third and fourth orders. Scale bars $=50 \mathrm{~mm}$.

marginal and medial parts of the leaf. Margins smooth with no papillae or hairs. Abaxial surface characterized by abundant stomata arranged in longitudinal rows. Adaxial surface characterized by scarce stomata.

\section{Descrição}

Aspectos morfológicos. Os fósseis correspondem a fragmentos de ramos vegetativos compostos por ramificações de $1^{\mathrm{a}}, 2^{\mathrm{a}}, 3^{\mathrm{a}}$ e $4^{\mathrm{a}}$ ordens. Os ramos de $1^{\mathrm{a}}$ ordem medem 6,5 a 2,0 $\mathrm{mm}$ de largura e $289 \mathrm{~mm}$ de comprimento. Os ramos de $2^{\mathrm{a}}$ ordem variam de 3,9 a $6,5 \mathrm{~mm}$ de largura (moda $=3,9 \mathrm{~mm}$ ) e de 21,1 a $72,5 \mathrm{~mm}$ de comprimento (moda $=46,5$ $\mathrm{mm})$. Os ramos de $3^{\mathrm{a}}$ ordem variam de 1,9 a $3,8 \mathrm{~mm}$ de largura $($ moda $=3,0 \mathrm{~mm})$ e de 6 a $68 \mathrm{~mm}$ de comprimento $($ moda $=21$ $\mathrm{mm}$ ) e os ramos de $4^{\mathrm{a}}$ ordem variam de 0,8 a $1,8 \mathrm{~mm}$ de largura $($ moda $=1,4 \mathrm{~mm}$ ) e de 10,0 a 36,1 mm de comprimento (moda $=21,6 \mathrm{~mm}$ ). Os fragmentos de $4^{\mathrm{a}}$ ordem podem apresentar nas porções apicais, adensamentos de folhas.

Os ramos de todas as ordens apresentam-se densamente cobertos por folhas sésseis, bifaciais, decorrentes, heteromórficas, com nervura central conspícua freqüentemente de $0,4 \mathrm{~mm}$ de espessura, de margens lisas e dispostas espiraladamente. As folhas lineares retas (Figuras 3 e 4), inseridas em ângulo agudo, possuem comprimento que varia de 3,0 a $15,1 \mathrm{~mm}(\operatorname{moda}=$ $9,0 \mathrm{~mm})$ e largura de 0,8 a $2,0 \mathrm{~mm}(\operatorname{moda}=1,0 \mathrm{~mm})$ apresentando predominantemente ápice agudo ou arredondado, ou ainda bífido, em menor freqüência. As folhas lineares falcadas (Figuras 3 e 4 ), inseridas predominantemente em ângulo agudo ou em baixa freqüência reto, possuem comprimento que varia de 2,5 a $20,0 \mathrm{~mm}(\operatorname{moda}=10 \mathrm{~mm})$ e largura de 0,5 a $2,5 \mathrm{~mm}(\operatorname{moda}=$ $1,0 \mathrm{~mm}$ ) apresentando ápice agudo ou arredondado predominantemente, ou ainda bífido ou recortado, em menor freqüência. Particularmente no ramo de $1^{\mathrm{a}}$ ordem (Figura 4), as folhas lineares falcadas atingem comprimentos e larguras superiores às das outras ordens, variando de 23,0 a $32 \mathrm{~mm}$ (moda $=24,0 \mathrm{~mm}$ ) de comprimento 

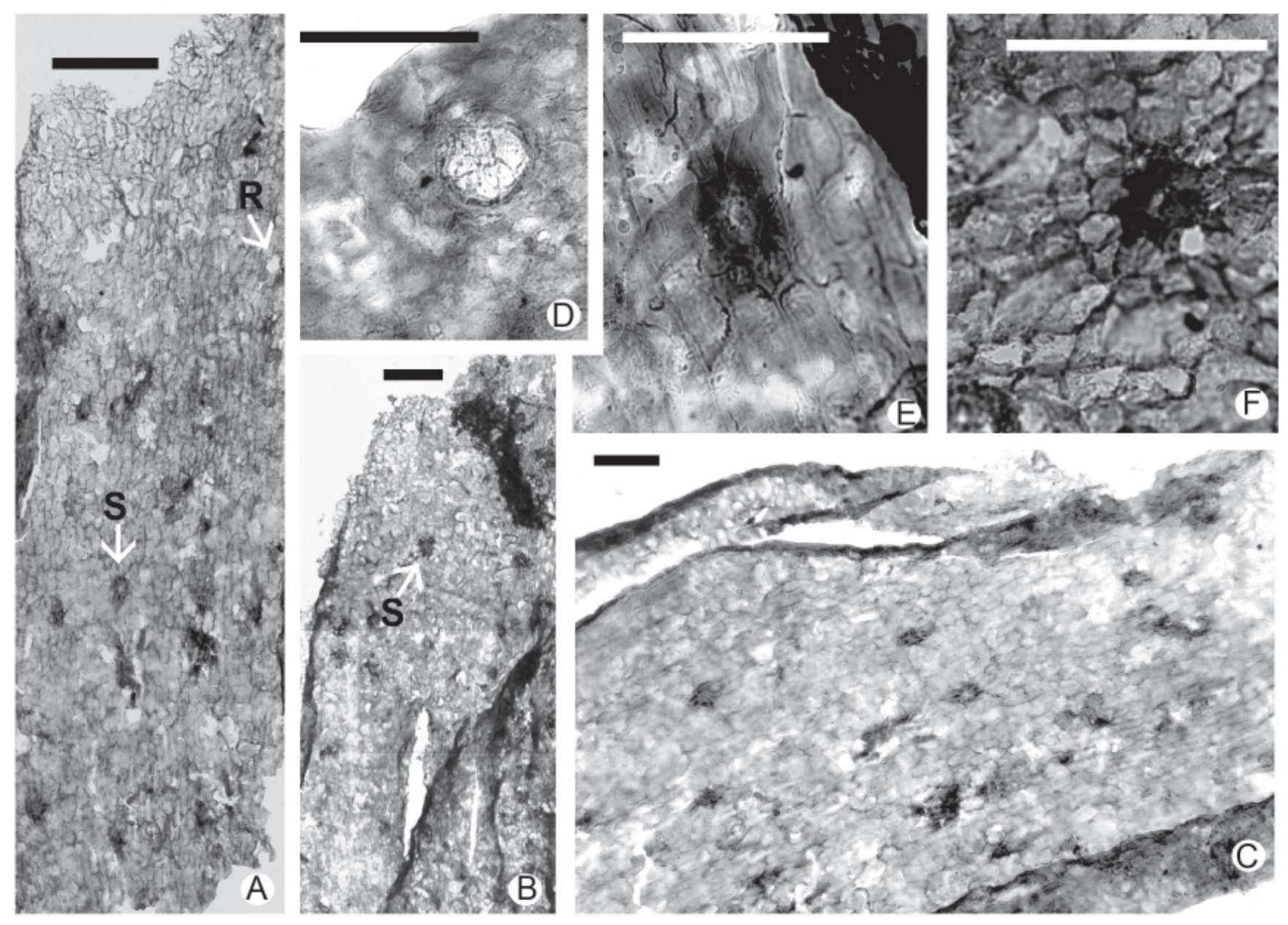

Figura 5. Krauselcladus canoinhensis emend. Aspectos anatômicos: A, GP/3E 6014 (lâm. 11), epiderme abaxial; B, GP/3E 6014 (lâm. 21 ), epiderme adaxial; C, GP/3E 4913 (lâm. 9), estômatos dispostos em fileiras; D, GP/3E 6014 (lâm. 21), ducto resinífero esquizógeno marginal; E, GP/3E 4913 (lâm. 6), estômato afundado, abundantes pontuações nas paredes celulares; F, GP/3E 4913 (lâm. 9), estômato rodeado por células polimórficas. Escala $=200 \mu \mathrm{m}$ em B, escalas $=100 \mu \mathrm{m}$ em A, C-F. Abreviaturas: S, estômato; R, ducto resinífero.

Figure 5. Krauselcladus canoinhensis emend. Anatomical aspects: A, GP/3E 6014 (slide 11), abaxial epidermis; B, GP/3E 6014 (slide 21), adaxial epidermis with lax groups of stomata; C, GP/3E 4913 (slide 9), stomata rows, abaxial face; D, GP/3E 6014 (slide 21), schizogenous resin duct; E, GP/3E 4913 (slide 6), sunken stoma, cell walls with abundant pits; F, GP/3E 4913 (slide 9), stoma surrounded by polymorphic cells. Scale bar $=200 \mu \mathrm{m}$ for B, scale bars $=100 \mu \mathrm{m}$ for A, C-F. Abbreviations: S, stoma; R, resin duct.

e variando de 1,3 a 3,0 $\mathrm{mm}(\operatorname{moda}=2,6 \mathrm{~mm})$ de largura. As folhas lobadas (Figura 3), predominantemente inseridas em ângulo reto, possuem comprimento que varia de 9,5 a $19,5 \mathrm{~mm}(\operatorname{moda}=15,9 \mathrm{~mm})$ e largura de 0,8 a $1,3 \mathrm{~mm}$ (moda $=1,2 \mathrm{~mm}$ ), podendo ser bi ou multilobadas, com lobos arredondados e nervura central conspícua dividindo-se conforme o número dos lobos.

Aspectos anatômicos. Vista paradermal. Ambas as faces apresentam células epidérmicas da porção proximal polimórficas com cinco ou seis lados, variando de 45 a 390 $\mathrm{mm}(\operatorname{moda}=61 \mathrm{~mm})$ de comprimento e 13 a $31 \mathrm{~mm}(\operatorname{moda}=$ $16 \mathrm{~mm}$ ) de largura, para as pentagonais e variando de 135 a $475 \mathrm{~mm}(\operatorname{moda}=240 \mathrm{~mm})$ de comprimento e 14 a $32 \mathrm{~mm}$ $(\operatorname{moda}=18 \mathrm{~mm})$ de largura, para as hexagonais; gradativamente sendo substituídas por células retangulares na porção médio-distal da folha, inclusive na nervura central conspícua. Células retangulares variam de
35 a $480 \mathrm{~mm}(\operatorname{moda}=190 \mathrm{~mm})$ de comprimento e de 7 a 37 $\mathrm{mm}(\operatorname{moda}=10 \mathrm{~mm})$ de largura. As células epidérmicas apresentam paredes anticlinais grossas levemente sinuosas e com abundantes pontuações. Os estômatos são haploqueílicos, afundados, rodeados por 5 a 8 células subsidiárias, medindo 14 a $22 \mathrm{~mm}(\operatorname{moda}=20 \mathrm{~mm}) \mathrm{de}$ comprimento e 10 a $16 \mathrm{~mm}(\operatorname{moda}=12 \mathrm{~mm})$ de largura, dispostos em fileiras longitudinais quando abundantes ou dispostos em grupos laxos. O poro estomático, no eixo maior do diâmetro, mede de 16 a $22 \mathrm{~mm}$. Os ductos resiníferos são esquizógenos, de paredes grossas, com 5 a 8 células da parede, medindo $3,2 \mathrm{~mm}$ de largura, dispostos em fileiras longitudinais localizadas nas porções marginal e mediana da folha. Margens são lisas sem papilas e tricomas. A face abaxial é caracterizada por abundantes estômatos dispostos em fileiras longitudinais. Face adaxial caracterizada por escassos estômatos. 


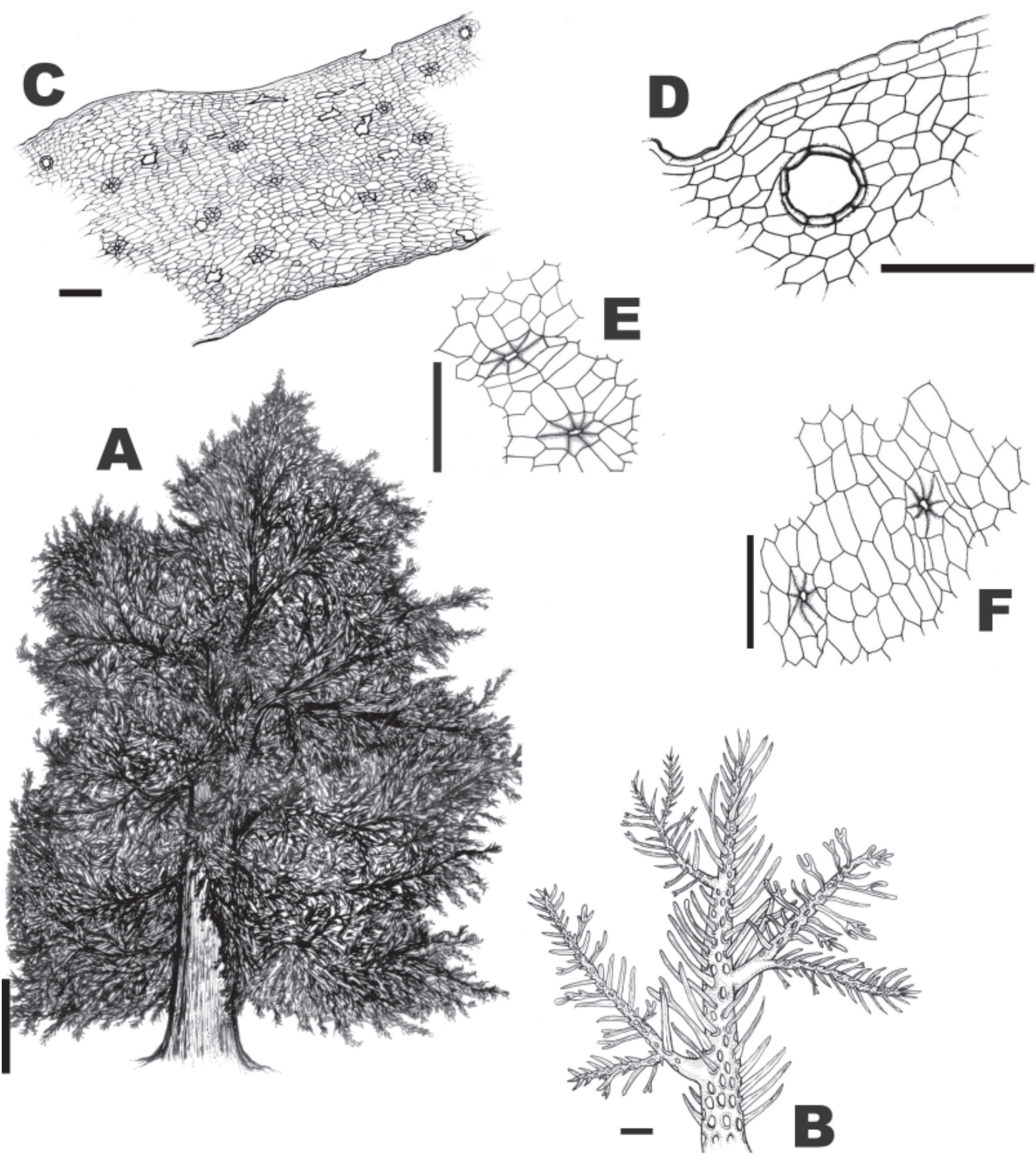

Figura 6. Morfologia e anatomia de Krauselcladus canoinhensis: A, reconstrução artística da conífera, escala = $1 \mathrm{~m}$; $\mathbf{B}$, ramo coberto por folhas heteromórficas lineares e lobadas, escala $=10 \mathrm{~mm}$; $\mathbf{C}$, epiderme abaxial com margens lisas, escala = $10 \mu \mathrm{m} ; \mathbf{D}$, ducto resinífero, escala $=40 \mu \mathrm{m} ; \mathbf{E}$, estômatos e células polimórficas, escala $=40 \mu \mathrm{m} ; \mathbf{F}$, estômatos e células retangulares, escala $=40 \mu \mathrm{m}$.

Figure 6. Morphology and anatomy of Krauselcladus canoinhensis emend.: A, artistic reconstruction of the conifer, scale bar = $1 \mathrm{~m}$; $\mathbf{B}$, branch densely covered with linear and lobed leaves, scale bar $=10 \mathrm{~mm}$; C, abaxial face, smooth margin, scale bar $=10 \mu \mathrm{m}$; $\mathbf{D}$, resin duct, scale bar $=40 \mu \mathrm{m} ; \mathrm{E}$, sunken stomata surrounded by polymorphic cells, scale $=40 \mu \mathrm{m} ; \mathrm{F}$, sunken stomata surrounded by rectangular cells, scale bar $=40 \mu \mathrm{m}$. 


\section{DISCUSSÃO}

Os exemplares de ramos estudados exibem caracteres próprios de Krauselcladus, tais como folhas heteromórficas, inteiras, dispostas espiraladamente, com variações na forma dos ápices (arredondado, agudo ou bífido), base decorrente e nervura central conspícua. Cabe ressaltar que associados às cutículas estudadas foram encontrados grãos-de-pólen bissacados, possivelmente da mesma espécie.

A diagnoses e descrições de Yoshida $(1968,1970)$ apresentam imprecisões, fato que prejudica a identificação das duas espécies propostas: $K$. canoinhensis e $K$. catarinensis (Tabela 1). O autor não quantificou com medidas as ordens de ramificação, o que dificulta a atribuição para cada exemplar, pois em muitos casos os ramos não se encontram organicamente conectados, impedindo sua inclusão dentro de alguma das ordens de ramificação (Figuras 3, 4 e 6B). Da mesma maneira, as medidas das folhas não foram fornecidas apenas dimensionadas como longas ou curtas (Tabela 1).

Yoshida $(1968,1970)$ utilizou a heteromorfia como caráter decisivo na distinção das duas espécies, exclusivamente em relação às folhas da primeira ordem de ramificação. A distinção, a partir deste caráter, torna-se confusa, já que no presente estudo se observou a heteromorfia nas demais ordens de ramificação $\left(2^{\mathrm{a}}, 3^{\mathrm{a}}\right.$ e $4^{\mathrm{a}}$ ordens). Quanto à forma da folha, proposto de maneira imprecisa por Yoshida, optou-se pela delimitação de dois morfótipos básicos de folha: linear e lobado, sendo que ambos possuem dois subtipos, aqui mencionados na Tabela 1 e exibidos nas Figuras 3, 4 e 6B.

Quanto à filotaxia, Yoshida (1970) descreve como "geralmente sendo espiralada para K. catarinensis e em todas as ordens". Contudo, na diagnose de Krauselcladus, os ramos de $4^{\mathrm{a}}$ ordem têm a sua filotaxia classificada como "semelhante àquela do sistema de ramificação", considerada "irregular quase dística", contrariarando a descrição da espécie $K$. catarinensis. Com relação à $K$. canoinhensis, a filotaxia só é mencionada para os ramos de $1^{\mathrm{a}}$ ordem.

$\mathrm{Na}$ diagnose de Krauselcladus e de K. canoinhensis (Yoshida, 1970), a forma dos ápices, é descrita como sendo "arredondada" nas folhas dos ramos de $2^{\mathrm{a}}, 3^{\mathrm{a}}$ e $4^{\mathrm{a}}$ ordens. Contudo, este caráter não é informado para os ramos de $1^{\text {a }}$ ordem, densamente cobertos por folhas de ápice arredondado. A descrição de $K$. catarinensis não inclui a forma dos ápices (Figuras 3, 4 e 6B). O presente estudo permitiu reconhecer, além de ápices arredondados, duas morfologias do caráter não descritos por Yoshida (1970): agudo (folhas lineares retas e falcadas) e bífido (folhas lineares retas), os quais foram incluídos na diagnose emendada proposta.

O padrão de nervura foi descrito por Yoshida como "uninervado e sulcado" para K. catarinensis. Após a presente análise não se constatou a diferença entre o padrão uninervado e o padrão uninervado sulcado, proposto por Yoshida $(1968,1970)$ como caráter específico. O caráter sistema fasciculado de ápice dos ramos de $4^{\mathrm{a}}$ ordem, também utilizado pelo autor na separação das duas espécies, não foi constatado no presente estudo.

A grande maioria dos ramos estudados apresentou folhas com cutículas preservadas. A partir destas realizou-se um estudo anatômico que permitiu sinonimizar as duas espécies de Krauselcladus com Krauselcladus canoinhensis, espécietipo do gênero (Yoshida, 1970). Esta decisão foi baseada no fato de que não foram encontradas diferenças epidérmicas entre as cutículas estudadas (Figura 5), tomando-se especial cuidado em se obter cutículas de distintos ramos portadores de folhas de morfótipos distintos e também de amostras variadas. A presença de ductos resiníferos esquizógenos (rodeados por células - Figuras 5D e 6D) permitiu a inclusão de Krauselcladus dentro da Ordem Coniferales, já que se trata de uma estrutura típica do grupo, encontrada no mesófilo das folhas, córtex e com menor freqüência no lenho (Sporne, 1965; Esau, 1976; Stewart \& Rothwell, 2001). Embora possíveis ductos resiníferos tenham sido descritos para Voltziales, esses não são esquizógenos, ou seja, não possuem células epiteliais ao redor (são lisígenos), diferenciando-se dos encontrados na ordem Coniferales que podem apresentar uma ou duas fileiras de células em volta (Esau, 1976; Stewart \& Rothwell, 2001).

Em Yoshida (1968), os estômatos de Krauselcladus foram classificados como anomocíticos, com 5 a 8 células subsidiárias (Tabela 1). No atual estudo conferiu-se que as células subsidiárias diferenciam-se em tamanho e forma das restantes células epidérmicas, portanto essa classificação não foi considerada válida (Figuras 5A, 5B, 5C, 5E, 5F, 6C, 6E e 6F). Dessa forma, optou-se por denominar os estômatos como haploqueílicos, classificação mais adequada para as gimnospermopsidas (Gifford \& Foster, 1988; Kerp, 1990).

$\mathrm{Na}$ Argentina, em camadas das formações Andapaico e El Trampeadero (Carbonífero Superior) da bacia do Paganzo foi descrita a espécie Krauselcladus argentinus (Archangelsky, 1978; Archangelsky \& Cúneo, 1991) com base em fragmentos de ramos de no máximo $1 \mathrm{~mm}$ de largura, cobertos por folhas decorrentes homomórficas de $0,5 \mathrm{~mm}$ de largura e 5-7 mm de comprimento, com ápices agudos e retos. Ao comparar os resultados aqui obtidos com $K$. argentinus nota-se que essa espécie apresenta algumas semelhanças com $K$. canoinhensis (Tabela 1), embora a falta de dados anatômicos para a espécie argentina impeça comparações mais elaboradas com o material brasileiro. As folhas somente retas de ápices agudos e retos, examinadas por Archangelsky (1978), também foram observadas nas amostras aqui estudadas de K. canoinhensis. Desta maneira, tais características não são suficientes para serem consideradas como caracteres específicos, já que no gênero Krauselcladus pode se encontrar uma ampla gama de combinações entre os caracteres foliares. Archangelsky (1978) menciona que as imprecisões na descrição de Krauselcladus e a ausência de dados anatômicos impedem o estabelecimento dos caracteres qualitativos mais importantes desse gênero, problemas que foram 
Tabela 1. Comparação dos caracteres morfológicos e anatômicos de Krauselcladus com base na literatura e no presente estudo. O símbolo ? significa dado não informado na literatura; e hífen significa dado inexistente.

Table 1. Comparison of the morphological and anatomical characteristics of Krauselcladus (based on the literature and this study). The symbol ? means data not informed in the literature; and the hyphen means inexistent data.

\begin{tabular}{|c|c|c|c|c|c|c|c|}
\hline & & Ordens & $\begin{array}{c}\text { Krauselcladus } \\
\text { Yoshida }\end{array}$ & $\begin{array}{c}\text { K. canoinhensis } \\
\text { Yoshida }\end{array}$ & $\begin{array}{l}\text { K. catarinensis } \\
\text { Yoshida }\end{array}$ & $\begin{array}{l}\text { K. argentinus } \\
\text { Archangelsky }\end{array}$ & $\begin{array}{l}\text { Krauselcladus } \\
\text { presente estudo }\end{array}$ \\
\hline \multirow{10}{*}{ 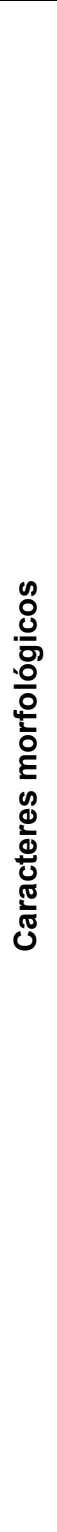 } & Heteromorfia & $\begin{array}{c}1^{\mathrm{a}} \\
2^{\mathrm{a}}, 3^{\mathrm{a}} \\
4^{\mathrm{a}}\end{array}$ & $\begin{array}{c}\text { presente ou ausente } \\
\text { ausente } \\
?\end{array}$ & $\begin{array}{c}\text { presente } \\
? \\
?\end{array}$ & $\begin{array}{c}\text { ausente } \\
? \\
?\end{array}$ & $\begin{array}{c}- \\
- \\
\text { ausente }\end{array}$ & presente \\
\hline & $\begin{array}{l}\text { Forma da } \\
\text { folha }\end{array}$ & $\begin{array}{c}2^{a}, 3^{a} \\
4^{a}\end{array}$ & $\begin{array}{l}\text { monomorfia: reta. } \\
\text { heteromorfia: reta ou } \\
\text { lobada, côncava } \\
\text { adaxialmente } \\
\text { inteira, reta, curva e } \\
\text { linear cuneiforme } \\
\text { inteira, reta, linear } \\
\text { cuneiforme }\end{array}$ & $\begin{array}{l}\text { 1. inteira, lanceolada, } \\
\text { reta } \\
\text { 2. lobada, côncava } \\
\text { inteira curva e linear } \\
\text { cuneiforme } \\
\text { inteira, reta e } \\
\text { ligeiramente curva }\end{array}$ & $\begin{array}{c}\text { reta levemente } \\
\text { côncava adaxialmente } \\
\text { lanceolada, inteira e } \\
\text { reta. } \\
\text { curva e cuneiforme, } \\
\text { inteira e côncava } \\
\text { adaxialmente }\end{array}$ & linear reta & $\begin{array}{l}\text { linear (reta ou falcada) e } \\
\text { lobada (bi ou multilobada) }\end{array}$ \\
\hline & $\begin{array}{c}\text { Tamanho } \\
\text { da folha } \\
\text { (comp x larg } \\
\text { em mm) }\end{array}$ & $\begin{array}{c}1^{\mathrm{a}} \\
2^{\mathrm{a}}, 3^{\mathrm{a}} \\
4^{\mathrm{a}}\end{array}$ & $\begin{array}{c}\text { longa (em ambas) } \\
\text { longa } \\
?\end{array}$ & $\begin{array}{c}\text { 1. curta, 2. longa } \\
? \\
?\end{array}$ & $\begin{array}{c}\text { longa } \\
\text { longa } \\
?\end{array}$ & $\begin{array}{c}- \\
- \\
5 \text { a } 7 \times 0,5\end{array}$ & $\begin{array}{c}\text { linear reta }(3,0 \text { a } 15,1 \times \\
0,8 \text { a } 2,0), \text { linear falcada } \\
(2,5 \text { a } 20,0 \times 0,5 \text { a } 2,5) \mathrm{e} \\
\text { lobada }(9,5 \text { a } 19,5 \times 0,8 \text { a } \\
1,3)\end{array}$ \\
\hline & Nervura & $\begin{array}{c}1^{\mathrm{a}} \\
2^{\mathrm{a}}, 3^{\mathrm{a}} \\
4^{\mathrm{a}}\end{array}$ & $\begin{array}{c}\text { uninervada (em } \\
\text { lobada, com nervura } \\
\text { ramificando-se } \\
\text { conforme lobos) } \\
\text { uninervada } \\
? \\
\end{array}$ & $\begin{array}{l}\text { uninervada (em } \\
\text { lobada, com nervura } \\
\text { ramificando-se } \\
\text { conforme lobos) } \\
\text { uninervada } \\
\text { uninervada } \\
\end{array}$ & $\begin{array}{l}\text { uninervada sulcada. } \\
\text { uninervada sulcada } \\
\text { uninervada sulcada }\end{array}$ & $\begin{array}{l}- \\
- \\
?\end{array}$ & $\begin{array}{l}\text { nervura central conspícua } \\
\text { (em lobada, ramifica-se } \\
\text { conforme } \mathrm{n}^{\circ} \text { de lobos). }\end{array}$ \\
\hline & Filotaxia & $\begin{array}{c}1^{a} \\
2^{a}, 3^{a} \\
4^{a}\end{array}$ & $\begin{array}{c}\text { espiralada } \\
? \\
\text { semelhante à do sist. } \\
\text { de ramificação } \\
\end{array}$ & $\begin{array}{c}\text { espiralada } \\
? \\
?\end{array}$ & $\begin{array}{l}\text { espiralada } \\
\text { espiralada } \\
\text { espiralada }\end{array}$ & $\begin{array}{c}- \\
- \\
\text { espiralada }\end{array}$ & espiralada. \\
\hline & $\begin{array}{l}\text { Ângulo de } \\
\text { inserção } \\
\text { das folhas }\end{array}$ & $\begin{array}{c}1^{a} \\
2^{a}, 3^{a} \\
4^{a} \\
\end{array}$ & $\begin{array}{c}\text { reta: abertas em } \\
\text { ângulo reto. } \\
\text { agudo (constricto para } \\
\text { o eixo) ou quase reto } \\
\text { com ápice para cima } \\
? \\
?\end{array}$ & $\begin{array}{l}\text { 1. agudo, } 2 \text {. quase } \\
\text { reto } \\
\text { agudo (constricto em } \\
\text { alguns pontos) mas } \\
\text { geralmente reto } \\
?\end{array}$ & $\begin{array}{c}\text { ligeiramente agudo } \\
\text { (constricto na base). } \\
\text { agudo } \\
? \\
\end{array}$ & agudo & $\begin{array}{l}\text { agudo (linear reta), agudo } \\
\text { ou reto (linear falcada) e } \\
\text { reto (lobada) }\end{array}$ \\
\hline & Ápice & $\begin{array}{c}1^{\mathrm{a}} \\
2^{\mathrm{a}}, 3^{\mathrm{a}} \\
4^{\mathrm{a}}\end{array}$ & $\begin{array}{c}? \\
\text { arredondado } \\
\text { arredondado }\end{array}$ & $\begin{array}{c}\text { ? } \\
\text { arredondado voltado } \\
\text { para cima } \\
\text { arredondado }\end{array}$ & $\begin{array}{l}? \\
? \\
?\end{array}$ & $\begin{array}{c}- \\
- \\
\text { agudo }\end{array}$ & $\begin{array}{l}\text { agudo, arredondado ou } \\
\text { bífido (linear reta), agudo } \\
\text { ou arredondado (linear } \\
\text { falcada) e lobos } \\
\text { arredondados (lobada) }\end{array}$ \\
\hline & $\begin{array}{c}\text { Sistema } \\
\text { fasciculado } \\
\text { de ápice } \\
\end{array}$ & $4^{a}$ & presente ou ausente & $\begin{array}{l}\text { presente nos ramos } \\
\text { de } 4^{a} \text { ordem }\end{array}$ & $\begin{array}{c}\text { ausente nos ramos de } \\
4^{\mathrm{a}} \text { ordem. }\end{array}$ & $?$ & não observado \\
\hline & $\begin{array}{l}\text { Sistema de } \\
\text { ramificação }\end{array}$ & & $\begin{array}{l}\text { irregular (quase } \\
\text { dístico) }\end{array}$ & $\begin{array}{l}\text { monopodial, ramos } \\
\text { laterais esparsos, } \\
\text { irregularmente dispôs- } \\
\text { tos quase dísticos }\end{array}$ & $?$ & $?$ & possivelmente monopodial \\
\hline & $\begin{array}{c}\text { Base da } \\
\text { folha }\end{array}$ & & decorrente & decorrente & decorrente & decorrente & decorrente \\
\hline \multirow{7}{*}{ 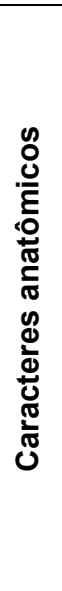 } & $\begin{array}{l}\text { Células da } \\
\text { epiderme }\end{array}$ & & $?$ & $?$ & $?$ & - & $\begin{array}{c}\text { retangulares ou polimórfi- } \\
\text { cas (paredes grossas } \\
\text { sinuosas, abundantes } \\
\text { pontuações) }\end{array}$ \\
\hline & $\begin{array}{c}\text { Tipo de } \\
\text { Estômato }\end{array}$ & & anomocítico & $\begin{array}{l}\text { monocíclico do tipo } \\
\text { anomocítico }\end{array}$ & $\begin{array}{l}\text { monocíclico do tipo } \\
\text { anomocítico }\end{array}$ & - & haploqueílicos, afundados \\
\hline & $\begin{array}{l}\text { Disposição } \\
\text { dos } \\
\text { Estômatos } \\
\end{array}$ & & $?$ & $?$ & $?$ & - & $\begin{array}{c}\text { fileiras longitudinais } \\
\text { (quando abundantes) ou } \\
\text { grupos laxos }\end{array}$ \\
\hline & $\begin{array}{l}\mathrm{N}^{\circ} \text { de células } \\
\text { subsidiárias }\end{array}$ & & $\begin{array}{c}5 \text { a } 8 \text { (tamanho e } \\
\text { forma variáveis, } \\
\text { formando um único } \\
\text { anel) }\end{array}$ & $\begin{array}{c}5 \text { a } 8 \text { (de tamanho e } \\
\text { forma variáveis, } \\
\text { formando um único } \\
\text { anel) }\end{array}$ & $\begin{array}{c}5 \text { a } 8 \text { (de tamanho e } \\
\text { forma variáveis, } \\
\text { formando um único } \\
\text { anel) }\end{array}$ & - & 5 a 8 \\
\hline & $\begin{array}{l}\text { Ductos } \\
\text { resiníferos }\end{array}$ & & - & - & - & - & $\begin{array}{l}\text { presente (refletido na } \\
\text { epiderme da folha) }\end{array}$ \\
\hline & Margem & & - & - & - & - & lisa \\
\hline & Papilas & & - & - & - & - & ausente \\
\hline
\end{tabular}


solucionados pelo presente estudo. Análises posteriores poderão esclarecer as afinidades de tais espécies.

Estabelecendo-se comparações de Krauselcladus com outros gêneros de coníferas neopaleozóicas gonduânicas (com caracteres anatômicos conhecidos) é explícita a diferença. O gênero Buriadia (Guerra-Sommer \& Bortoluzzi 1982; Ricardi-Branco, 1998; Singh et al., 2003) apresenta somente estômatos em uma das faces, rodeados por células subsidiárias com papilas, sendo Krauselcladus anfiestomático e sem papilas (figuras 5A-F, 6C, 6E e 6F). Não há ductos resiníferos nas folhas de espécie alguma de Buriadia (B. heterophylla, B. isophylla e B. figueirensis), diferente de Krauselcladus.

Em comparação ao gênero Paranocladus (RicardiBranco, 1998), são verificadas diferenças em nível morfológico: quanto à forma (escamiforme ou linear) e dimensões das folhas (menores em Paranocladus). A nível anatômico, verifica-se a ausência de tricomas e papilas em Krauselcladus (Figuras 5A-F, 6C-F) e a ausência de ductos resiníferos nas folhas de Paranocladus.

Em relação a Walkomiella, existem profundas diferenças em nível morfológico, uma vez que a última apresenta folhas escamiformes homomórficas. Anatomicamente, Walkomiella possui epiderme papilosa, estômatos apenas na face adaxial dispostos em duas zonas intercostais sem pêlos (Surange \& Singh, 1953; Hoeg \& Bose, 1960). Nenhum desses caracteres é encontrado em Krauselcladus.

Ao comparar anatomicamente Krauselcladus com gêneros de coníferas permianas e triássicas encontradas na porção norte do Pangea das famílias Majonicaceae, Ullmanniaceae e Palissyaceae, é possível verificar que em nenhuma delas encontram-se ductos resiníferos refletidos na epiderme como no caso de Krauselcladus, apesar de Majonicaceae e Ullmanniaceae incluírem gêneros com folhas anfiestomáticas, de estômatos monocíclicos dispostos em fileiras descontínuas (Taylor \& Taylor, 1993).

\section{CONSIDERAÇÕES FINAIS}

O gênero Krauselcladus é o único representante de Coniferales do Guadalupiano (Permiano "Médio") da bacia do Paraná descrito até o presente. Krauselcladus foi posicionado dentro da Ordem Coniferales devido à presença de ductos resiníferos esquizógenos do mesófilo refletidos na epiderme, caráter comum às coníferas.

$K$. canoinhensis e $K$. catarinensis foram sinonimizadas com $K$. canoinhensis, com base nas semelhanças a nível epidérmico. A espécie $K$. argentinus descrita por Archangelsky (1978) para a bacia Paganzo não contém dados anatômicos, portanto a comparação restringiu-se ao nível morfológico.

A presença de cutículas grossas, abundantes pontuações nas espessas paredes das células epidérmicas, estômatos afundados e ductos resiníferos refletidos na epiderme (Fahn, 1990) podem ser consideradas adaptações estruturais xeromórficas decorrentes de hábitats com deficiência hídrica fisiológica, associados por exemplo, a ventos sazonais (Pyykko, 1966). Sander (1987) também constatou que coníferas permianas provavelmente ocupavam áreas de solos mais secos, nos divisores de água. Ziegler (1990), em suas reconstruções paleofitogeográficas, indicou ocorrências de coníferas em regiões transicionais para bacias evaporíticas em situações em que chuvas eram marcadamente sazonais. Condições relativamente secas são corroboradas também por outras evidências na Formação Teresina (Rohn, 1994, 1997; Rohn et al., 2004).

Especulações acerca da tafonomia de Krauselcladus podem ser feitas já que a única ocorrência comprovada destes ramos, em Canoinhas, deve representar uma situação excepcional no contexto do amplo ambiente deposicional da Formação Teresina (Rohn \& Lavina, 1993; Milani, 1997; Rohn et al., 2004).

A ótima preservação dos tecidos (carbonificação) sugere rápido sepultamento dos ramos num ambiente subaquático. Considerando que estas coníferas provavelmente habitavam o interior do continente, em áreas com deficiência hídrica fisiológica, é possível que as respectivas comunidades tenham se aproximado ou afastado da bacia conforme as variações do clima e as quedas ou subidas do nível relativo da água dos ambientes deposicionais. Desta forma, gretas de contração abaixo do arenito com Krauselcladus (Figura 2) parecem evidenciar uma longa fase de freqüentes exposições subaéreas, provavelmente relacionadas a condições mais secas, quando as comunidades com as coníferas podem ter chegado mais próximas ao ambiente deposicional. Sob influência de uma ou mais fortes tempestades, os ramos de coníferas devem ter sido destacados das árvores, rapidamente transportados e depositados.

Desta forma, o acesso de elementos xerófitos à bacia não envolveu transporte necessariamente longo, o que explicaria o seu bom estado preservacional. Situação similar foi sugerida para ramos de Voltziales (?) do afloramento de Quitéria (Formação Rio Bonito) por Jasper et al. (2005). No caso da Formação Teresina, em vista da restrição das coníferas a um único afloramento, julga-se que a grande aproximação da comunidade xerófita à bacia pode ter sido uma situação excepcional, talvez controlada por mais fatores, além dos climáticos e eustáticos, tais como a paleogeografia. Cabe lembrar que a borda leste original da bacia foi erodida (Milani, 1997), faltando elementos para interpretações mais precisas.

\section{AGRADECIMENTOS}

Os autores agradecem ao Instituto de Geociências da Universidade de São Paulo (IGc-USP) e ao Instituto de Geociências e Ciências Exatas da Universidade Estadual de São Paulo Júlio de Mesquita Filho - Campus de Rio Claro (UNESP- Rio Claro) por terem cedido o material para a realização do estudo. Agradecem também aos revisores que com seus valiosos comentários enriqueceram o trabalho. 


\section{REFERÊNCIAS}

Anderson, J. \& Anderson, H. 1985. Palaeoflora of southern Africa: Prodromus of South African megafloras Devonian to Lower Cretaceous. Pretoria, A.A. Balkema, 423 p.

Anderson, J.; Anderson, H.; Archangelsky, S.; Bamford, M.; Chandra, S.; Dettmann, M.; Hill, R.; Mcloughlin, S. \& Rösler, O. 1999. Patterns of Gondwana plant colonization and diversification. Journal of African Earth Sciences, 28(1):145167.

Archangelsky, S. 1978. Nuevos elementos paleoflorísticos de la Formación Trampeadero (Carbónico), Sierra de Ambato, Provincia de La Rioja. Ameghiniana, 15(3-4):429-439.

Archangelsky, S. \& Cúneo, R. 1991. The Neopaleozoic floristic succession from northwestern Argentina. A new perspective. In: INTERNATIONAL GONDWANA SYMPOSIUM, 7, 1988. Proceedings, São Paulo, USP, p. 469-481.

Clement-Westerhof, J.A. 1984. Aspects of Permian palaeobotany and palynology. IV. The conifer Ortiseia Florin from the Val Gardena Formation of the Dolomites and the Vicentinian Alps (Italy) with a revised concept of the Walchiaceae (Göppert) Schimper. Review of Palaeobotany and Palynology, 41(1/2):51166.

Clement-Westerhof, J.A. 1987. Aspects of Permian palaeobotany and palynology. VII. The Mojonicaceae, a new family of Late Permian conifers. Review of Palaeobotany and Palynology, 52(3/ 4):375-402.

Clement-Westerhof, J.A. 1988. Morphology and Phylogeny of Paleozoic Conifers. In: C.B. Beck (ed.) Origin and Evolution of Gymnosperms, Columbia University Press, p. 298-337.

Crowley, T.J. \& North, G.R. 1991. Paleoclimatology. New York, Oxford University Press, 349 p.

Dimichele, W.A. \& Demaris, P.J. 1987. Structure and dynamics of a Pennsylvanian-age Lepidodendron forest: Colonizers of a disturbed swamp habitat in the Herrin (No 6) Coal of Illinois. Palaios, 2(2):146-157.

Esau, K. 1976. Anatomia de Plantas com Sementes. $2^{\text {a. }}$ ed., São Paulo, Editora Edgard Blücher Ltda, 294 p.

Fahn, A. 1990. Plant Anatomy. 4 ed., Oxford, Pergamon Press, $558 \mathrm{p}$.

Gastaldo, R.A. 1986. Implications on the paleoecology of autochtonous lycopods in clastic sedimentary environments of the Early Pennsilvanian of Alabama. Palaeogeography, Palaeoclimatology, Palaeoecology, 53(2-4):191-212.

Gifford, E. \& Foster, A.S. 1988. Morphology and evolution of vascular plants. $3^{\mathrm{a}}$ ed., New York, W.H. Freeman and Company, $626 \mathrm{p}$.

Guerra-Sommer, M. \& Bortoluzzi, C.A. 1982. Conífera (?) com estrutura epidérmica preservada no Gondwana sul-riograndense (Formação Rio Bonito, Candiota). In: CONGRESSO BRASILEIRO DE GEOLOGIA, 32, 1982. Anais. Salvador, SBG, vol. 4, p. 1235-1245.

Hoeg, O.A. \& Bose, M.N. 1960. The Glossopteris Flora of the Belgian Congo. Annales du Musée Royal du Congo Tervuren (Belgique), Série 8, Sciences géologiques, 32:1-106.

Jasper, A.; Ricardi-Branco, F. \& Guerra-Sommer, M. 2005. Coricladus quiteriensis gen. et sp. nov., a new conifer in Southern-Brazil Gondwana (Lower Permian, Paraná Basin). Anais da Academia Brasileira de Ciências, 77(1):157-168.

Kerp, H. 1990. The study of fossil gymnosperms by means of cuticular analysis. Palaios, 5:548-596.

Kerp, H. 1996. Post-Variscan late Palaeozoic northern hemisphere gymnosperms: the onset to the Mesozoic. Review of Palaeobotany and Palynology, 90(3/4):263-285.

Meyen, S.V. 1997. Permian conifers of Western Angaraland. Review of Palaeobotany and Palynology, 96(3/4):351-447.

Milani, E.J. 1997. Evolução tectono-estratigráfica da bacia do Paraná e seu relacionamento com a geodinâmica fanerozóica do Gondwana Sul-Ocidental. Curso de Pós-graduação em Geociências, Instituto de Geociências, Universidade Federal do Rio Grande do Sul, Tese de Doutorado, 228 p.

Pant, D.D. 1982. The lower Gondwana gymnosperms and their relationships. Review of Palaeobotany and Palynology, 37(1/2):55-70.

Pant, D.D. 1996. The biogeography of the late Palaeozoic floras of India. Review of Palaeobotany and Palynology, 90(1/2):70-98.

Pyykko, M. 1966. The leaf anatomy of East patagonian xeromorphic plants. Anneles Botanici Fennici, 3:453-622.

Ricardi-Branco, F.S. 1998. Tafoflora gondvânica do Membro Triunfo Formação Rio Bonito (Eopermiano), no município de Figueira, PR. Programa de Pós-Graduação em Geologia Sedimentar, Universidade de São Paulo, Tese de Doutorado, $182 \mathrm{p}$.

Rohn, R. \& Lavina, E.L. 1993. Cronoestratigrafia do Grupo Passa Dois. In: SIMPÓSIO CRONOESTRATIGRAFIA DA BACIA DO PARANÁ, 1, 1993. Resumos, Rio Claro, UNESP, p. 77-80.

Rohn, R. 1994. Evolução ambiental da bacia do Paraná durante o Neopermiano no leste de Santa Catarina e do Paraná. Programa de Pós-Graduação em Geologia Sedimentar, Universidade de São Paulo, Tese de Doutorado, 386 p.

Rohn, R. 1997. Plant megafossil occurrences in the Teresina and Rio do Rasto formations (Upper Permian of the Paraná Basin) in the state of Santa Catarina, Brazil. Revista Geociências Universidade de Guarulhos, número especial, 5:49-57.

Rohn, R.; Tognoli, F.M.W. \& Meglhioratti, T. 2004. Ichnogênero Thalassinoides na Formação Teresina (Grupo Passa Dois, Permiano, Bacia do Paraná), na região de SapopemaCongonhinhas (PR). In: CONGRESSO BRASILEIRO DE GEOLOGIA, 42, 2004. Anais, Araxá, UFMG.

Sander, P.M. 1987. Taphonomy of the Lower Permian Geraldine Bonebed in Archer Country, Texas. Palaeogeography, Palaeoclimatology, Palaeoecology, 61(3/4):221-236.

Singh, K.J.; Rothwell, G.W.; Mapes, G. \& Chandra, S. 2003. Reinvestigation of the coniferophyte morphospecies Buriadia heterophylla Seward and Sahni, with reinterpretation of vegetative diversity and putative seed attachments. Review of Palaeobotany and Palynology, 127(1/ 2):25-43.

Sporne, K.R. 1965. The morphology of Gymnosperms. $1^{\text {a }}$ ed., London, Hutchinson University Library, 216 p.

Stewart, W.N. \& Rothwell, G.W. 2001. Palaeobotany and the evolution of plants. $2^{\mathrm{a}}$ ed., London, Cambridge University Press, $521 \mathrm{p}$.

Surange, K.R. \& Singh, P. 1953. The female dwarf shoot of Walkomiella indica, a conifer of Lower Gondwana of India. The Palaeobotanist, 2:45-50.

Taylor, N. \& Taylor, L. 1993. The biology and evolution of fossil plants. New Jersey, Prentice Hall, 982 p. 
Yoshida, R. 1968. Descrição preliminar de coníferas neopaleozóicas da bacia do Paraná. Universidade de São Paulo, Dissertação de Mestrado, 54 p.

Yoshida, R. 1970. Novo gênero de conífera da Formação Estrada Nova, Norte do Estado de Santa Catarina. Rio de Janeiro, Departamento Nacional da Produção Mineral, Divisão de Geologia e Mineralogia, 17 p. (Boletim 249)

White, M.E. 1998. The Greening of Gondwana. $3^{\mathrm{a}}$ ed., Australia, Kangaroo Press, 256 p.
Wing, S.L. \& Sues, H.D. 1992. Mesozoic and early Cenozoic terrestrial Ecosystems. In: A.K. Behrensmeyer; J.D. Damuth; W.A. DiMichele; R. Potts; H.D. Sues \& S.L. Wing (eds.) Terrrestrial ecossistems throught time: evolutionary paleoecology of terrestrial plants and animals. The University of Chicago Press, p. 324-416.

Ziegler, A.M. 1990. Phytogeographic patterns and continental configurations during the Permian period. In: W.S. MacKerrow, \& C.R. Scotese (eds.) Palaeozoic palaeogeography and biogeography. Geological Society Memoir, 12:363-379.

Received in July, 2005; accepted in April, 2006 